\title{
Emergent Meaning Structures: \\ A Socio-Semantic Network Analysis of Artistic Collectives
}

Pre-print version

\author{
Nikita Basov \\ Centre for German and European Studies \\ St. Petersburg State University \\ Wouter De Nooy \\ Department of Communication Science \\ University of Amsterdam \\ Aleksandra Nenko \\ Institute for Design and Urban Studies \\ ITMO University
}




\section{Abstract}

This paper explores meaning structures in the social practice of small groups. While social and institutional fields impose meaning structures, they are put to practice (emerge) in the context of specific activities that take place within a field. Collaborating in small groups, field participants form such practical contexts. It enables playing on gaps and overlaps among imposed meaning structures and joint creation of emergent meaning structures that define them as a social group. Difficult to capture, emergent meaning structures are largely disregarded by institutional and field perspectives on meaning structures. As a consequence, the importance of collective practice to meaning structures is underrated.

We investigate imposed and emergent meaning structures in artistic collectives. The field of contemporary art does not impose its meaning structure explicitly, so meaning structures that emerge in artistic practice are relatively free to vary across social groups. In particular, we study two St. Petersburg collectives of artists, who intensely interact with each other and engage in joint creative work and exhibitions. We show that these collectives elaborate their own meaning structures within the framework of fieldspecific meaning structures, blending meanings corresponding to the different fields and field positions occupied by members of the collective.

The duality of semantic and social structure is central to the notion of meaning structures. We use word collocations in natural language as semantic structure and interaction ties as social structure in a mixed methods socio-semantic network analysis. In this approach, social networks help to understand semantic networks.

Keywords: meaning structure, field, interaction, practice, mixed methods, art. 


\section{Introduction}

In this paper, we accentuate the relevance of collective practice in small groups to meaning structures within a social field. Institutional and field theories hold that meaning structures are imposed, for instance, by 'objective relations' (Bourdieu 1996; Bourdieu and Johnson 1993) or by institutions (DiMaggio 1986; Mohr 1994, 2000; Mohr and Neely 2009). However, there are different fields (Bourdieu 1996; Bourdieu and Johnson 1993) and different institutional orders in society (Friedland and Alford 1991), and individuals are able to play on gaps and inconsistencies between imposed cultural constructs (Bourdieu 1990; Bourdieu and Wacquant 1992; Friedland and Alford 1991). Joining in groups, supporting each other and engaging in shared practice, agents create group-specific culture that Fine (1979) termed 'idioculture'. Implementing imposed meaning structures associated with different fields or positions, groups often blend them to develop their own meaning structures (De Nooy 2003). Hence, meaning structures imposed by fields are not merely reproduced, which opens up the possibility of change. An account of meaning structures not considering these idiosyncratic meaning structures is incomplete, limiting its capacity to explain the evolution of meaning structures in fields and the interaction between cultural structures of different fields and positions.

Structural approaches to meaning, to which we reckon our current work, conceptualize meaning structures as a duality of meanings and social structure (Mohr 1998). Institutional and field theories, as indicated in the preceding paragraph, focus on macrostructure, e.g., the objective relations between positions in social fields that are at the same time relations between cultural categories. Anyone involved in a field or institution is subjected to the field's meaning structure, so we say that the meaning structure is imposed. We argue, however, that in practice social structure is also linked to meanings at the level of small groups of interacting people: Interpersonal interactions are the force that allows small groups to transform imposed meaning structures into meaning structures that are shared within the group and thus identify the group. We call these emergent meaning structures because imposed meaning structures are put to practice in the interactions and statements of a group; they take shape and are shaped.

In some organizational and institutional contexts, directives and other formal statements explicitly impose meaning structures (e.g., Mohr 1994). Here, official documents can be coded and then analyzed to investigate imposed meaning structures (Mohr 1994, 1998; Mohr and Lee 2000; Mohr and Neely 2009; Yeung 2005). This, however, is not the case if we want to capture emergent meaning structures that transform formally stated meaning structures, so we have to adjust the method of measuring meaning structures. Simultaneously, we remain within the framework of the duality of social structure and meaning structures. Meaning structure is measured as semantic networks, that is, collocation of concepts in the verbal expressions of the artists. Social structure is measured as cohesive subgroups in networks of interpersonal interaction. Our core assumption is that meaning is constituted by the social context, so associations between concepts that are shared by members of the same social group reflect the meaning structure of this group. The combination of meaning and social structures, then, boils down to comparing concept associations within and among subgroups in social networks. Simple and straightforward as this method may be, such an approach has, to the best of our knowledge, not yet been proposed (comp., e.g., Breiger and Puetz 2015; Carley 1994; Danowski 1982; Erickson 1988; Nerghes et al. 2015; Pachucki and Breiger 2010; Schultz and Breiger 2010; Vaisey and Lizardo 2010). 
To substantiate our theoretical argument, we analyze meaning structures and interpersonal relations in artistic collectives: groups of creatives engaging in collective production and/or representation of artworks. Artistic collectives are a suitable case in point. On the one hand, from the work of Bourdieu (Bourdieu 1996; Bourdieu and Johnson 1993), quite a lot is known about the forces operating in fields of contemporary art and the meaning structures they impose. As a result, we know how to recognize imposed meaning structures in the case of artistic collectives. On the other hand, in artistic fields symbolic capital is strongly associated with originality. Therefore, artists are eager to express reinterpretations, i.e., emergent meaning structures, thus producing rich textual data suitable for our purposes.

In particular, we focus on two collectives in St. Petersburg, Russia, each of which unites members who have been cooperating intensely for a long time. In this context, clearly recognizable meaning structures may well have emerged. The two collectives occupy similar niches within the Russian contemporary art field but they include individuals with quite diverse positions, including differences in backgrounds and fields of practice. This selection of cases allows us to account both for similarities of meaning structures across the collectives imposed by the artistic field and for differences across and within collectives attributable to different fields, positions, practices, and interaction patterns. We examine extensive corpora of texts, sociometric data, and ethnographic data gathered during the two years of our ethnographic studies of the collectives.

\section{Meanings imposed by fields and meanings emerging in group practice}

In their seminal work, Friedland and Alford (1991) proposed a duality perspective on society as an interinstitutional system that both sets material patterns of activity and develops symbolic systems that categorize individuals and activities, thus ordering reality and providing sense to things. According to this institutional perspective, field-specific institutional logics impose both social structure and the meaning of positions within the structure (Breiger 2000, 2005; Mohr 2000; Thornton et al. 2012). It has been shown empirically how institutions, for example, welfare organizations (Mohr 1994), universities (Mohr and Lee 2000) or city administrations (Meyer et al. 2012), group individuals both materially and symbolically, bringing them together, ascribing similar identities to them, and instructing them with certain meanings. This leads to a duality of social positions and meanings: Distinct meanings are institutionally attached to individuals or groups occupying particular social positions.

The institutional approach has also highlighted the existence of multiple institutional logics in society. The degree of consensus on classificatory principles, according to which meanings are assigned to positions, may vary (Bian et al. 2005; Mohr 1994). This results in inconsistencies between meanings and positions. As Friedland and Alford (1991) argue, such gaps and overlaps are often used by individuals and groups to manipulate and reinterpret meanings imposed by institutions playing with different material, historical, or social contexts and choosing institutional logics, role identities, and activities better suiting their current needs (compare the concept of switching between netdoms in (Gondal and McLean 2013; Mische and White 1998; White 1992). For example, someone promoting a subordinate who is also one's son is acting as a parent who is expected to support the child instead of acting as a manager who is expected to treat 
all employees equally. Throughout this process individuals attempt to understand themselves and the world. There is a "meaningfulness of relational systems that enable and constrain action" (Mohr and Rawlings 2010, p. 16).

Bourdieu's field theory has a similar dual approach to the relation between social structure and meaning. Bourdieu theorizes fields as "spaces of objective relations that are the site of a logic and a necessity" (Bourdieu and Wacquant 1992, p. 97). Fields correspond to areas of social life, like art, academia, and religion, which consist of objective relations as well as shared understandings of what goes on in the field (Bourdieu 1983, 1996; Bourdieu and Johnson 1993). Objective relations fundamentally structure fields according to both social properties held by agents in certain positions and categories of perceptions used by the agents (high/low, masculine/feminine, large/small, etc.). The latter constitute cultural categorizations that are shared by members of the field, especially by those who occupy similar positions (Bourdieu 1998; Bourdieu and Wacquant 1992). In this way, objective relations impose meanings on members of a field.

Neither institutional theory nor field theory describes the relevance of interpersonal interactions to the meaning structures shared by members of an institution or field. Meanwhile, there are good reasons to believe that interactions matter. De Nooy (2003) argued that interpersonal relations such as interaction are relevant to field theory because, on the one hand, interpersonal interactions "mediate and transform the effect of objective relations" (Ibid., p. 323). On the other hand, individuals in one field may engage in interactions with individuals in other fields, "bringing to bear properties and qualifications characteristic of another field" (Ibid., p. 323), giving rise to new meanings comprising hybrid classifications, stigmata and identities, in turn affecting the structure of cultural categories. "In the process new symbolic distinctions and values are being created or existing ones are being reaffirmed or discarded" (De Nooy 2003, p. 323).

The relation between interaction and symbolic production proposed by De Nooy is just one among a number of perspectives that link networks of interpersonal relations to culture. As DiMaggio stresses, "network analysis is the natural methodological framework for empirically developing insights from leading theoretical approaches to cultural analysis" (DiMaggio 2011, p. 286). Attitudes, opinions, and tastes were shown to reproduce through interactions and therefore to rely on interpersonal ties (Carley 1986; Erickson 1996; Umphress et al. 2003). More recently, similarity in perceptions and meanings has been argued to affect interpersonal relations (Dahlander and McFarland 2013; Vaisey and Lizardo 2010). Overall, culture and interpersonal ties are increasingly seen as mutually constitutive and therefore, dual (Breiger and Puetz 2015; Mützel 2009; Pachucki and Breiger 2010; Schultz and Breiger 2010).

This literature suggests an intimate relation between interaction and meaning. From the perspective of meaning structure as a combination of social structure and meanings, we may expect that individuals who are structurally grouped by interpersonal interactions strive towards shared meanings. In their verbal expressions and discussions, they instantiate/express transformed elements of the meaning structure imposed by the field. Thus, they establish a manifest or emergent meaning structure, which is guided both by the meaning structure imposed by the field and by the characteristics of their joint practice. As a consequence, emergent meaning structures may vary across social groups within the same field. In particular, we expect adapted meaning structures to appear where different fields or institutions collide, for example, when members of different fields interact in heterogeneous groups. 
Importance of group interaction to meanings has been particularly emphasized by a rich research tradition of studies of art including Becker (1982) that has shown how repetitive and intense interactions among artists develop into conventions and correlated schemes of behavior in an art world. According to Farrell (2003) collaborative circle theory, engagement in discussions and mutual support in their coordinated practice enable groups of artists to develop and promote unconventional shared 'visions', which are the core of an art group's culture. These visions guide the collective work of artists, coordinate their artistic styles, their techniques and topics. Supporting each other emotionally throughout joint communication and practice, group members are able to probe the boundaries and gain new insights, reinforce them and promote them broader (Farrell 2003), that may later become part of institutionalized cultural constructs (see Godart and White 2010).

\section{Socio-semantic approach to meaning structures}

Highly regulated meaning structures imposed by institutions have been fruitfully investigated by coding words ascribed to individuals in similar social positions and words corresponding to institutional practices into a limited set of categories; then the relations between the two types of categories are formally analyzed (Mohr 1994, 1998; Mohr and Lee 2000; Mohr and Neely 2009). Yet, production of emergent meanings in collective practice of small groups is far less regulated. There, one should not expect expressions to be "succinct and formalistic, <... loosely coupled from the demands of conforming to objective practice" (Mohr and Neely 2009, p. 220) and to converge on a limited set of conventional categories that a researcher or an expert can detect externally. Any categorization would imply that a researcher imposes certain categories on the textual data (for an extensive discussion see Lee and Martin 2015), which is particularly problematic if we want to investigate how individuals reshape meaning structures interacting in practice. Instead of coding texts, prior to interpretation we map meanings expressed by the informants (as recommended in Mohr 1998, p. 366).

How can we map meaning from verbal expressions and link it to social structure to obtain meaning structures? We assume that associations between concepts that are shared by members of the same social group reflect a meaning structure that characterizes this group. This is meaning in the sociolinguistic sense of what words mean within a particular social context. We are evidently less interested in the dictionary meaning of words; we take semantics in the strict linguistic sense for granted. Instead, we look at textual structures larger than the single word or concept to go beyond dictionary meaning.

We employ another relational approach to language that has argued that words derive their meaning from their relations with other words (De Saussure and Hidayat 1988; Wittgenstein 1953). We focus on how individuals associate (collocate) concepts in their verbal statements, e.g., within a sentence (Sinclair 1991). This approach aligns with co-occurrence-based semantic network analysis (Carley 1994; Diesner 2013; Lee and Martin 2015; Nerghes et al. 2015), a technique that starts with a corpora of texts rather than with a set of predefined categories and results in maps of links between word stems - traditionally named 'concepts' -as they co-occur within a certain interval in these texts.

Concepts may co-occur in sentences for lots of reasons, ranging from grammatical rules to slips of the tongue, hence the slightly derogatory bag-of-words label for co-occurrence-based approaches. We need 
additional information to select the co-occurrences of concepts that are relevant to the purpose of the analysis. In our case, we are interested in the individuals who produce the texts and the social relations among them, so we use the individuals and their social relations in our analysis of concept co-occurrences. This turns our analysis into a socio-semantic network analysis (Roth and Cointet 2010) rather than a plain semantic network analysis, which does not trace the relationships between the individuals and the concepts they use.

Each co-occurrence of a concept pair creates a concept link, which we assume to represent an association between the concepts. If we process texts by individual artists separately, we get different links for different artists in different contexts. For example, all members of artistic collectives use the concept art. However, their understanding of art may differ, which can be revealed by the relations between this concept and other concepts in their discourses. Some may associate art with transformation, culture, or history, while others associate it with canvas, brush, or palette. This signals that art is something different to them. Thus, we capture the polysemy that is inherent to a logic of practice that "never explicitly limits itself to any one aspect of the terms it links, <...> exploiting the fact that two 'realities' are never entirely alike in all respects, but are always alike in some respect, at least indirectly (that is, through the mediation of some common term) $<\ldots>$ like the keynote to the other sounds in a chord, to the other aspects, which persist as undertones" (Bourdieu 1990, p. 88).

We are interested in meanings shared by members of the same group. Because each pair of collocated concepts is linked to an individual producing the text, it is easy to aggregate links per individual into a semantic network of conceptual associations for this individual. It is also easy to computationally select links that different individuals share. If the individuals are structurally similar owing to the pattern of their interactions or membership of the same collective or field, the concept links that they share indicate the emergent meaning structure of the group, collective, or field. In this way, we relate meanings to the social structure of interpersonal relations and field positions. We can inspect formally detected intersections in concept links at the field level, presumably representing meaning structures imposed by the field. We can also examine meaning structures at the level of artistic collectives and at the level of subgroups within these collectives.

This aggregation approach is in line with Bourdieu's practice theory. In practical situations meanings are only partially expressed. Therefore, practice is to be captured across situations and time, as Bourdieu writes: "the cumulation and juxtaposition of relations of opposition and equivalence which are not and cannot be mastered by any one informant, never in any case at the same time, and which can only be produced by reference to different situations, that is, in different universes of discourse and with different functions, is what provides the analyst with the privilege of totalization" (Bourdieu 1990, p. 82). We have to aggregate meaning over different situations and individuals to capture the totalized effects of the dual influence of fields and practices.

Both collocation of concepts in text, which give rise to semantic networks, and network structure of interpersonal interaction (social networks) are quantitative approaches. We apply and advocate, however, a mixed methods approach combining semantic and social network data with qualitative interpretation of the texts and other ethnographic data available. In natural language, many word combinations have a grammatical rather than a socio-semantic reason. Intersection of these combinations across different persons does not reveal meaning structures, so they should be excluded. This can partly be done in a quantitative way, for example, by removing stop words (e.g., prepositions, interjections, articles), but it 
requires additional qualitative pruning. As a next step, qualitative analysis is needed to interpret the meaning of shared concept links from the specific context of sentences in which they occur. To understand (Verstehen) the meaning of the concept links, we have to revert to the texts from which they were taken. Similarly, group structure within a collective derived with social network analysis should be validated against the perceptions of groups and roles by the members of the collective.

\section{Data/Case studies}

This study investigates two artistic collectives from St. Petersburg, Russia, coded as PA and CH. Both were founded in 2003, both create contemporary visual art, and are characterized by intense interaction, strong interpersonal ties, and the joint artistic practice of its members. Yet, the two are different in organization, the educational and cultural backgrounds of members, understanding of art and its tasks, spatial embedding in the city space, and artistic styles. Importantly, PA includes only individuals occupying different positions within the Russian contemporary art field, while $\mathrm{CH}$ includes members of two fields: the art field and the academic field.

Artistic collectives are highly informal. In particular, membership in PA is open and flexible while $\mathrm{CH}$ members collaborate closely with other artists and intellectuals. In this analysis we only focus on participants with stable membership, which implies long-standing involvement in interaction and joint practice of the collectives, which we assume is a prerequisite for meaning structures to emerge.

PA includes eleven core members aged 20 to 65 . The distinctive feature of the collective is its exhibiting strategy. It 'occupies the bodies of other cultural institutions' and acts as a 'nomadic gallery' invading unconventional parts of conventional artistic spaces (e.g., a wall of a theatre or a corridor of an art-center where PA artists exhibit every two weeks), presenting works in everyday city spaces (e.g., a grocery shop or a public toilet), and performing in the city streets.

$\mathrm{CH}$ includes nine core members aged 30 to 50 , most of whom are tied by friendships lasting for decades. Thematically, the collective focuses on political issues and draws on ideas of the leftist critical theory (e.g., Gramsci, Brecht, Marx, Althusser). It is acknowledged in Russia as one of the major politically engaged artistic collectives. $\mathrm{CH}$ is well integrated in the international art scene and has gained considerable success there among grant-givers, art professionals and the public. Artwork formats are mixed and predominantly incorporeal: textual (e.g. a newspaper named after the group name), performative (e.g. musical shows the 'Songspiels'), and actionist (e.g., artistic demonstrations). The members are affiliated (often in quite high posts) with a variety of organizations in St. Petersburg and Moscow - educational and research institutions, publishing houses, museums, theatres, centers for contemporary art.

The data was collected in 2011 and 2012. Regarding our purposes, we distinguish between two main types of data: textual data and social network data. To map interpersonal relations between the members we used a sociometric survey providing them with the list of all other core participants and asking: 'How often do you interact?' The respondents were asked to choose from five options for each other member: almost never; 1 or less/month; 2-4 times/month; 5-14 times/month; 15 or more times/month. Seventeen out of twenty core members responded to the survey resulting in a response rate of $85 \%$. If 
members evaluated the frequency of their interactions with each other differently, we used the median of their reported tie frequencies.

Our main method of textual data collection was in-depth interviews with the artists. The interviewers asked up to 50 open-ended questions from a standard list, such as: 'How did your group form?'; 'How would you describe your relations with other members?'; 'What do you do together with other members?'; 'What is art to you?'; 'How would you describe your artistic style?'; 'Do you sell your works and how?'; 'What does viewer's reaction on your works mean to you?'; 'How do you communicate with the audience?'; 'How would you describe the artistic scene?'. The seventeen interviews lasted from 55 minutes to 5.5 hours, depending on the interviewee's endurance. We also collected texts written by members of the collectives having clearly identifiable authorship. The written texts include webpages, blogs, newspaper articles, poetry, novels, and so on. Finally, we did fourteen visual ethnographies in artistic studios and at exhibitions lasting for about two hours and registering the processes of individual and collective artistic work, informal communication between members, encounters of the artists with other creative professionals and broader publics, and preparation of exhibitions. Longer expressions in conversations witnessed during these observations were transcribed to produce additional textual data. For each of the members we collected at least one type of textual data.

We used all texts collected for a core member-the member's corpus-to map this person's semantic network. The following procedure was applied to each corpus separately. We started with marking stop words that we deemed irrelevant to meaning structures such as articles, particles, prepositions, and pronouns using delete lists that we constructed iteratively while going through the texts. Then we applied Porter's stemming procedure for the Russian language (all textual data was collected in Russian) to aggregate variants of the same word, e.g., singular and plural forms, to their stems by removing suffixes (Porter 1980). In semantic network analysis, these generalized forms of aggregated words are traditionally referred to as 'concepts' (see Carley 1986, 1994; Diesner 2013; Lee and Martin 2015; Nerghes et al. 2015). Table 1 presents the number of concepts per member per text type. These counts show the amount of textual information that we have for each member.

Finally, we created an undirected link between two concepts if the words from which the concepts derive appeared at least once next to each other in the member's texts. The concepts and their links constitute the undirected semantic network of a member. For example, if member A's textual corpus consisted only of the phrase 'Dima makes performances: Dima's performances attract people' and none of these words was identified as a stop word, the semantic network of A would consist of five concepts, namely Dima, performance, make, attract, people, and five links Dima-performance, make-performance, Dimamake, performance-attract, attract-people.

The number of links per semantic network is provided in Table 1. It shows that the size of the corpus of concepts varies among members as well as the source. For some members we have more textual material and larger semantic networks with more links than for other members. We think, however, that this is as it should be in a totalizing approach. Members who are more vocal are more likely to express and perhaps shape the communis opinio of a social group. 
Table 1. Overview of collected textual data: Total number of concepts per member per source type and the number of concept links per member.

\begin{tabular}{|c|c|c|c|c|c|c|c|}
\hline \multirow[t]{2}{*}{ Member } & \multirow[t]{2}{*}{ Type } & \multicolumn{3}{|c|}{ Concepts } & \multicolumn{3}{|c|}{ Concept links } \\
\hline & & Conversation & Interview & $\begin{array}{r}\text { Written } \\
\text { text }\end{array}$ & Total & Total & Shared \\
\hline CA & Artist & 0 & 3395 & 9270 & 12665 & 6918 & 839 \\
\hline $\mathrm{CB}$ & Artist & 0 & 2901 & 0 & 2901 & 1255 & 197 \\
\hline $\mathrm{CC}$ & Philosopher & 0 & 1646 & 20722 & 22368 & 12223 & 958 \\
\hline$C D$ & Artist & 0 & 1920 & 2614 & 4534 & 2405 & 359 \\
\hline CE & Philosopher & 0 & 0 & 8220 & 8220 & 4826 & 499 \\
\hline $\mathrm{CF}$ & Philosopher & 0 & 0 & 6668 & 6668 & 3994 & 434 \\
\hline CG & Philosopher & 0 & 3965 & 27276 & 31241 & 17911 & 1171 \\
\hline $\mathrm{CH}$ & Philosopher & 0 & 2453 & 2989 & 5442 & 2725 & 427 \\
\hline $\mathrm{Cl}$ & Artist & 0 & 928 & 0 & 928 & 356 & 79 \\
\hline $\mathrm{PA}$ & Artist & 0 & 536 & 0 & 536 & 165 & 40 \\
\hline$P C$ & Artist & 1656 & 2055 & 0 & 3711 & 1296 & 216 \\
\hline PD & Artist & 0 & 1813 & 0 & 1813 & 563 & 113 \\
\hline PE & Artist & 0 & 1288 & 0 & 1288 & 437 & 79 \\
\hline PF & Artist & 1307 & 920 & 0 & 2227 & 770 & 119 \\
\hline PG & Artist & 264 & 0 & 0 & 264 & 106 & 16 \\
\hline PI & Artist & 369 & 3551 & 0 & 3920 & 1434 & 182 \\
\hline PJ & Artist & 744 & 2664 & 782 & 4190 & 1509 & 210 \\
\hline PL & Artist & 853 & 0 & 0 & 853 & 289 & 46 \\
\hline PN & Artist & 0 & 1933 & 0 & 1933 & 556 & 123 \\
\hline PO & Artist & 0 & 3355 & 0 & 3355 & 1193 & 198 \\
\hline
\end{tabular}

The first letter in an acronym for a member refers to the collective: P for PA and C for $\mathrm{CH}$. The numbers under Conversation, Interview, and

Written text give the number of concepts collected for a member from texts of the specified type. Under Concept links, Total shows the number of distinct concept pairs for this member and Shared Links represents the number of these links also used by at least one other member of the two collectives.

In the subsequent analysis we account only for concept links shared within or across the collectives. For example, if the semantic networks of members $A$ and $B$ both contained the link make-performance, we would consider this link to be shared between A and B. Selected automatically, these shared links are fewer than in the initial semantic networks and can be manually inspected in network diagrams. Table 1 shows the number of links shared with at least one other member of the two collectives.

\section{Imposed and emergent meaning structures in two artistic collectives}

The analysis of our data proceeds in two stages. Firstly, we compare meaning structures between the two collectives. In order to do that, we: (1) automatically retrieve concept links shared in PA and in $\mathrm{CH}$ collectives separately; formally detect intersection of concept links between PA and in $\mathrm{CH}$, i.e., locate those of shared links that are shared in both of the collectives' semantic networks; and formally identify idiosyncratic links: the ones shared in only one of the two collectives, but not in the other one;

(2) compute the percentage of concept links that are shared across the collectives and the amount of links 
that are unique to each of the collectives; (3) examine concepts most frequently used in concept links and most frequent concept links out of those unique for PA and $\mathrm{CH}$ and those shared between them;

(4) interpret respective meaning structures by qualitatively inspecting our ethnographic and textual data to see if they are emergent or imposed. We expect meaning structures shared across the collectives to be imposed by the field of contemporary art. Meaning structures that are shared only within one collective may signal a position in the art field different from that of the other collective. If so, these meanings are probably also imposed-by the position. However, these meaning structures might equally have emerged from practice due to the interaction between members of the collective who have different field positions.

Secondly, we examine different groups within one of the collectives, $\mathrm{CH},-$ namely, a group of artists and a group of academic philosophers. We compare the meaning structures of these groups in a similar fashion to assess whether the central and frequently used meaning structures they share are likely to have emerged from the confrontation of group-specific meaning structures in the collective, in particular meaning structures related to different fields.

\subsection{Comparison of the two collectives}

The result of intersection procedure that yields concept links shared both by members of $\mathrm{CH}$ and members of PA, only by PA and only by $\mathrm{CH}$ is presented in Fig. 1. Concept links that are shared both by members of PA and members of $\mathrm{CH}$ may reveal meaning structures shared by the collectives. We regard concept links shared by at least two PA and two $\mathrm{CH}$ members as concept links shared by both collectives (grey lines in Fig. 1). Concept links shared by at least four $\mathrm{CH}$ members but less than two PA members are supposed to be links specific for $\mathrm{CH}$ (red lines in Fig. 1). For PA-specific concept links, we use a slightly lower threshold value, namely links shared by at least three PA members, to compensate for the fact that we have less textual material for PA than for $\mathrm{CH}$ (cyan lines in Fig. 1). The width of a link represents the number of members using it.

$\mathrm{CH}$ members idiosyncratically share $33,2 \%$ of links presented in Fig. 1, PA share $19,2 \%$ of links in the figure, while $47,6 \%$ of links are shared in both of the collectives. The statistics reveal significant consensus in the meaning structures of the groups: most of the shared links are the same across the collectives.

First, we see that art is an overwhelmingly central concept in the semantic network shared both by $\mathrm{CH}$ and PA members (Table 2). This concept was combined with other shared concepts 138 times. The focal concept link for $\mathrm{CH}$ and PA is contemporary-art (Table 2), that is used 79 times, which is 2,5 times more often than the second frequently used concept link piece-art (29 times). We may say that contemporary-art is central to the meaning structure shared by the two collectives. 


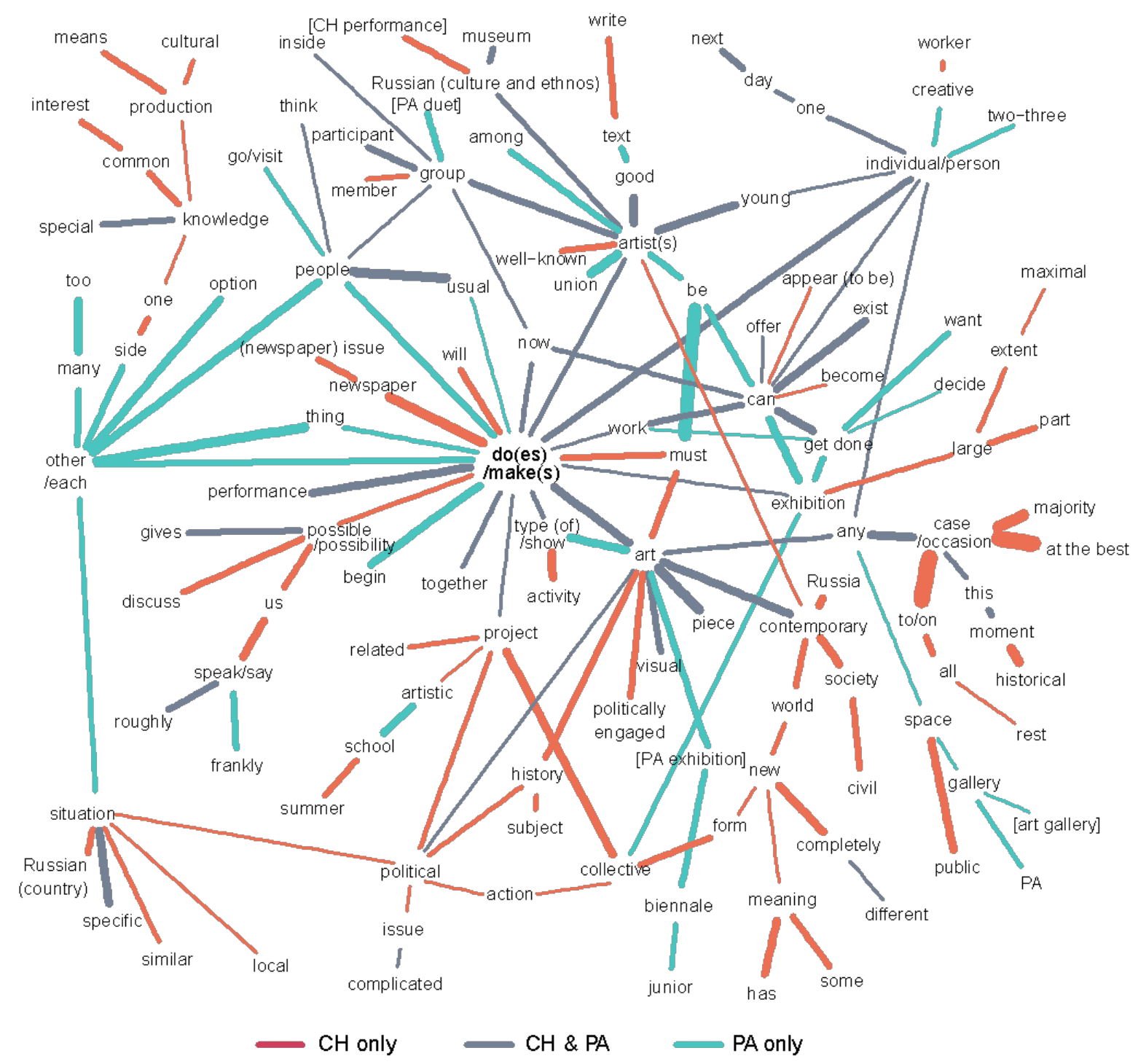

Fig. 1 Main component in the semantic network of shared concept links within or across artistic collectives

Table 2. Most frequent concept links, shared both in $\mathrm{CH}$ and in $\mathrm{PA}$, and concepts most frequently used in the shared links.

\begin{tabular}{lrrr}
\hline Concept & $\begin{array}{l}\text { Co-occurrences with } \\
\text { other concepts } \\
\text { (degree centrality) }\end{array}$ & Concept link & $\begin{array}{l}\text { Frequency } \\
\text { of usage }\end{array}$ \\
\hline art & 138 & contemporary-art & 79 \\
do(es)/make(s) & 96 & piece-art & 29 \\
contemporary & 79 & do(oes)/make(s)-exhibition & 25 \\
this & 40 & this-case/occasion & 23 \\
individual/person & 38 & this-moment & 17 \\
artist(s) & 35 & do(oes)/make(s)-work & 13 \\
group & 29 & young-artist(s) & 13 \\
piece & 29 & roughly-speak/say & 12 \\
case/occasion & 28 & visual-art & 12 \\
exhibition & 25 & do(oes)/make(s)-together & 11 \\
\hline
\end{tabular}


If we extract and inspect quotes that include the link contemporary-art, we find a number of normative statements on what is and what is not art as well as prescriptions of what art and artists should do. This is to be expected if Bourdieu is right in asserting that the core struggle within a field is the definition of what is good or valuable within the field. In this light, the meaning structures shared by the two artistic collectives are likely to be inevitable and in that sense imposed by the field of contemporary art in which the collectives operate. Some examples of quotes for both collectives (the first letter in an acronym for a member refers to the collective: $\mathrm{P}$ for $\mathrm{PA}$ and $\mathrm{C}$ for $\mathrm{CH}$ ):

If one makes some things for sale, one can do this to earn, but I don't see here any contemporary art, which is meant to unveil problems. (PD interview)

I think, it is like a conscious action. You may do something in contemporary art, but not posit yourself as a contemporary artist. It is this awareness that makes the difference. That is why I have a specific date when I started to make contemporary art. This is when I started making artworks out of tape. (PO interview)

Panic and exaltation, horror and delight, unrest, lack of balance - this is the pathos of contemporary art. (CG written text)

We would like to note that these types of normative statements occur in written texts, interviews, and group conversations. The written texts and conversations were not solicited or influenced by the researcher; they reflect practice as it unfolds. The interviews were less unobtrusive as they were solicited by and executed in the presence of a researcher. In our experience, however, members of artistic collectives were willing and seemingly at ease making normative statements about art and artistic practices in the interviews.

The impact of the field of contemporary art on the shared meaning structure is also evident from normative statements on what artists should do that employ other frequently used concept links shared by both by $\mathrm{CH}$ and PA. For instance, one of the most frequently ( 25 times) used shared links is doexhibition. The quotes with this link reflect the stereotypical perspective on the artist as a solitary and sovereign creator:

No, this is just a certain practice of an artist, he is becoming... If he does an exhibition or his own show, message is a product, which is public. Yes, family is an internal affair, while artist is a wider function, a social one. <...> No, of course, an artist is an individual creator. (PC interview)

Abandoned corpus of a factory, resembling Stalker by Tarkovsky. Ruins of the industrial Soviet past. On the top, through the holes in the roof, the light is pouring in. On the concrete slabs in the floods of the rainwater moss and fern are greening; if you squat, there is an illusion that you are looking at a small-scale earth, again as in Tarkovsky movies. It is silent as if in a church. This is a place where one should do exhibitions of contemporary art, says [CB]. Everybody agrees. (CG written text)

Expressions using the link contemporary-art also reflect a general belief of the field that art is important to the spectator but it is not easy to understand: 
There should be something coming from people... Somehow everyone should want. I mean, if a person has a wish to meet art he will see it in contemporary art too. The main thing in it is eureka occurring. It is important for the viewer to have an opportunity to interpret. (PF interview)

The thing is that nowadays, of course, visual art, contemporary art, in particular, has predominantly become, so to say, maybe, not understandable for the profane viewer, hasn't it? Ask yourself, what are these black hooks on a white [background], what are they telling you? And here, naturally, it is important to have an explanatory text by a critic or an artist, which explains his position. (PC interview)

From this point of view it is necessary, of course, to make contemporary art a fashion. One should make more art-projects, which involve people not from the art world. If I were the director of an institution, I would simply introduce such a rule - to do projects with people who are not involved in art at all. (CB interview)

The quotes presented above, which include links shared across the collectives, we think, substantiate our claim that the field of contemporary art affects the meaning structures expressed by its members. According to Bourdieu's field theory, however, we should also expect differences between collectives occupying different positions. "These distinctive signs produce existence in a world in which the only way to be is to be different, to 'make one's name', either personally or as a group." (Bourdieu and Johnson 1993, p. 106). Indeed, we see differences between the collectives' stances toward the institutions of the art field. Using the focal shared link, $\mathrm{CH}$ members stress the strength of their own position in the contemporary art field, their affiliations with dominant institutions of education, representation and evaluation:

Yet, for all these years we have produced certain material, and been a presence in the contemporary art field. $\mathrm{CH}$ is in great demand: there are several big exhibitions per year - from biennales to solo ones. And so myself, I have a job in Moscow, I am an editor of the [a leading journal on literature] and curate a poetical series, [CC] lectures in [two well-known St. Petersburg universities], [CE] lectures in Moscow, [CH] also works in [the leading literature journal] and for philosophers. (CG interview)

In contrast, PA members are ironic towards contemporary art. They directly express this orientation in their statements referring to the central concept link of the field (contemporary-art) (see below a quote from a discussion the exhibition 'Biennale of senior art' by PA, that is ironic about a sound mainstream 'Biennale of junior art') and in their art works (Fig. 2):

'Biennale of senior art'. Well, here the topic of art is already present.. We, as the workers of this forefront (laughter) ... There is also retrospection here. There is irony about what contemporary art is (PC conversation).

PA also speak in defense of weaker positions in the field. Here are their expressions with one of the frequently (13 times) used concept links shared by $\mathrm{CH}$ and $\mathrm{PA}$, young-artist:

I think it [Biennale of junior art] is a cool thing, because these biennales have a certain weight, this division into young and not young. New contemporary art is formed as a new unity. No, this division by age... there should be limits for Kandinsky [a prize in 
Russian contemporary art given to junior artists], one should not send [an application] after a certain age. Young artists there are under thirty five. (PF conversation)

PRO ARTE [a foundation for contemporary art] is a kind of infrastructure, you can ask for money to do a project there, they can give you a space. Not so long ago there was a discussion between artists and the curator of our group that young artists need studios and that PRO ARTE is thinking of organizing such a space. (PO interview)
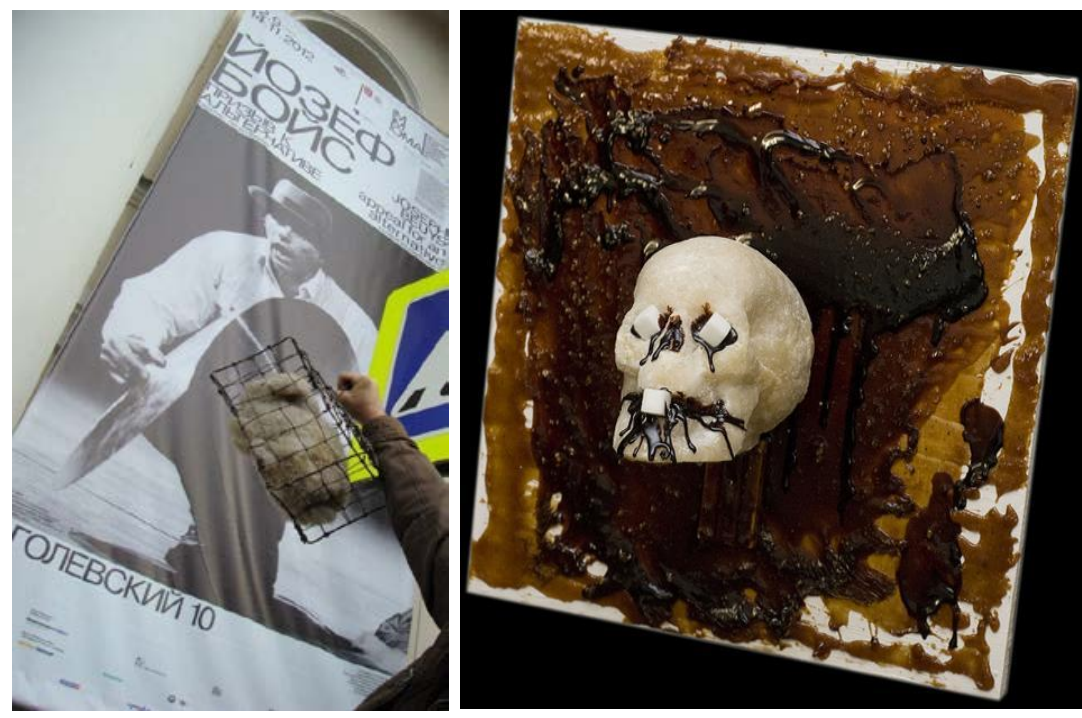

\section{Fig. 2 Artworks by PA}

Left to right: a performance by PA at J. Beuys' retrospective exhibition in Moscow in 2012 visiting the exhibition with a fake caged rabbit; a parody on D. Hirst's works by PA, attributed by them to Hirst himself.

In contrast, $\mathrm{CH}$ having a strong position in the field, express skepticism towards junior artists using the same shared concept link:

When I am teaching young artists I sometimes feel difficulties. Also everything has become too easy: cinema, video, architecture in $3 \mathrm{D}$, photography is transformed into sculpture. Everything looks great, however hollow, because there is no effort needed for manufacture. $<\ldots>>$ I understand curators very well: so, here is a young artist who could be given a credit of trust. He participates one time, another, but there is no guarantee that after the third time in the project he won't leave the track. It is a tough question. (CA interview)

The main difference between the meaning structures of the two collectives is their stance towards politics. For $\mathrm{CH}$ it is a substantial issue (Fig. 3). The members stress their very long career in politically engaged art in words and action using the shared focal link contemporary-art: 
We have been saying all the time, starting from 2002, that art is linked to politics, that contemporary art can't exist separately from it. (CA interview)
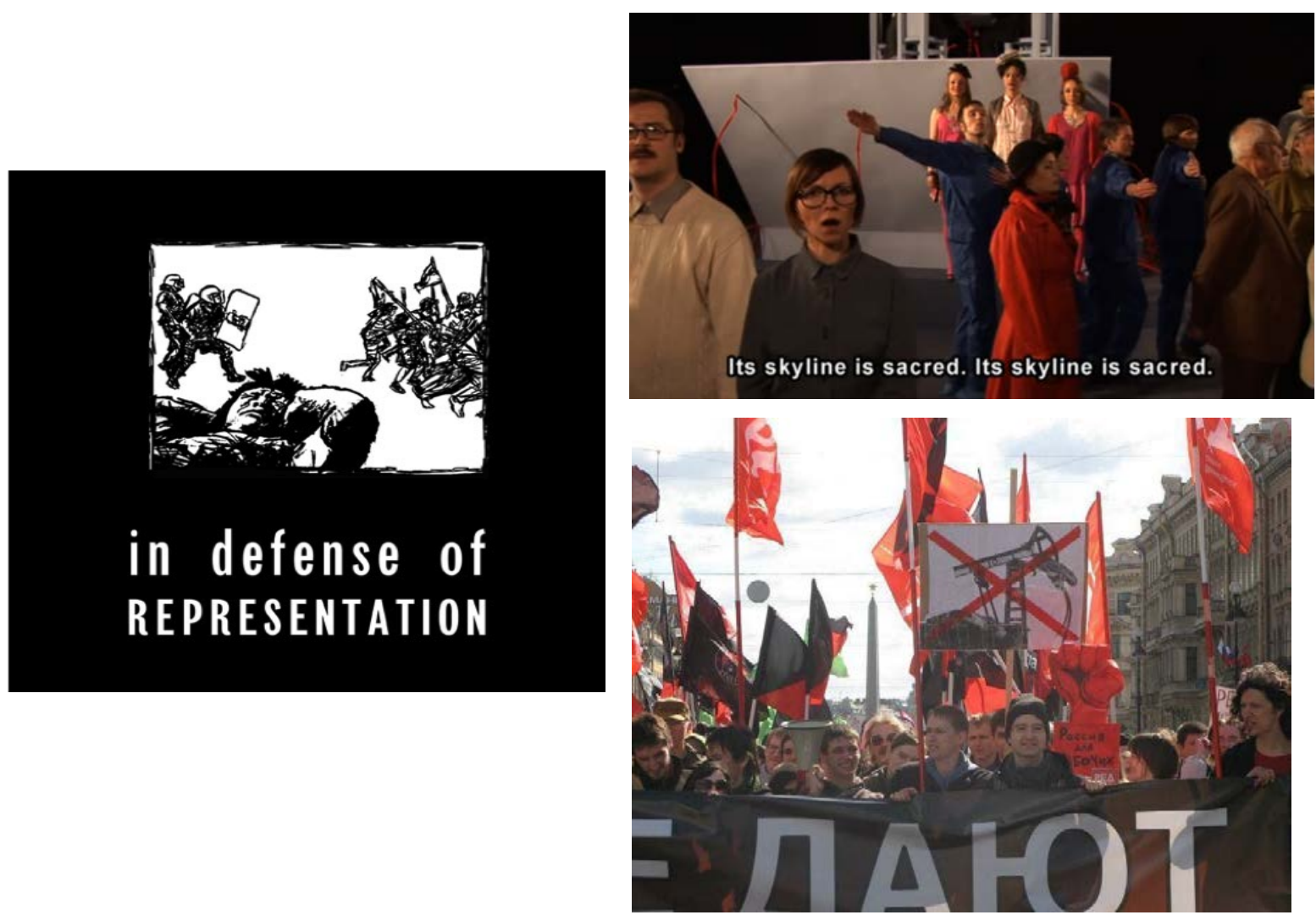

Fig. 3 Artworks by $\mathrm{CH}$

From the left, clockwise: a cover of one of $\mathrm{CH}$ newspaper issues; a frame from a Songspiel by $\mathrm{CH}$; a 1st of May demonstration linked to a performance by $\mathrm{CH}$.

Considering idiosyncratic semantic networks of the collectives, we further track the same differences. For $\mathrm{CH}$, the concept political is very central (Table 3 , see also orange lines around this concept in Fig. 1), used in concept links 31 times. Among their most frequently used idiosyncratic concept links are public-space, historical-moment, collective-action (Table 3). These links are used to express political engagement of the collective:

Many groups now use aesthetical forms to intervene into public space and just leave their traces, slogans, attacking the existing state of affairs. <...> Even if you do science, art, you should do it consciously and understand, how this will impact the political situation in the country, in the world. (CG interview). 
Table 3. Most frequently used concept links idiosyncratic to $\mathrm{CH}$ and PA and concepts, most frequently used in the idiosyncratic links

\begin{tabular}{|c|c|c|c|}
\hline PA & & $\mathrm{CH}$ & \\
\hline Concept & $\begin{array}{l}\text { Co-occurrences with } \\
\text { other concepts } \\
\text { (degree centrality) }\end{array}$ & Concept & $\begin{array}{l}\text { Co-occurrences with } \\
\text { other concepts (degree } \\
\text { centrality) }\end{array}$ \\
\hline be & 155 & side & 48 \\
\hline can & 111 & one & 48 \\
\hline other/each & 42 & new & 32 \\
\hline must & 38 & political & 31 \\
\hline [PA exhibition] & 21 & history & 29 \\
\hline get done & 20 & large & 28 \\
\hline exhibition & 16 & art & 26 \\
\hline art & 15 & contemporary & 25 \\
\hline biennale & 15 & situation & 23 \\
\hline side & 14 & meaning & 22 \\
\hline Concept link & Frequency of usage & Concept link & Frequency of usage \\
\hline can-be & 108 & one-side & 48 \\
\hline must-be & 38 & public_space & 21 \\
\hline other/each-side & 14 & new-form & 17 \\
\hline group -[PA duet $]$ & 12 & member-group & 16 \\
\hline [PA exhibition] -art & 12 & history-art & 14 \\
\hline frankly_speak/say & 11 & large-part & 14 \\
\hline biennale-[PA exhibition] & 9 & historical-moment & 12 \\
\hline get done-exhibition & 8 & collective-action & 11 \\
\hline other/each-thing & 7 & has-meaning & 10 \\
\hline junior-biennale & 6 & large-extent & 10 \\
\hline
\end{tabular}

The quotes using the link political-art shared by the two collectives reveal differences between $\mathrm{CH}$ and $\mathrm{PA}$ in how they view art. For $\mathrm{CH}$ :

Art is political by definition. New, or actual, art is denuding the political side of art, denying its alienation in the artwork (poesis) in favor of momentary but repeated action or gesture (praxis). The work does not disappear but is not considered as selfsufficient. (CG written text)

In contrast, PA use political-art to explain that they view political art as insincere, while emphasizing that being sincere is the main thing in art:

The main things are idea and sincerity. Their art is often insincere and makes an effect only by its scale. This is when a person lives in one environment and makes themes not inherent to him, some political art. For example, the military topics by [a well-known 
St. Petersburg artist], Islamic motives. We are closer to people, we make mud... (PO interview)

For PA, the concept political is peripheral, used only in the concept link political-art (Fig. 1) and absent in the list of most central concepts of the collective (Table 3 ). Among their most frequently used concept links (Table 3) one can't find anything that would indicate their concern with politics.

A collective's stance towards politics may result from the forces within the art field. Politically engaged art, such as pursued by $\mathrm{CH}$, claims less autonomy than art focused only on the art world itself, which seems to apply to PA. In field theory, the autonomous and heteronomous poles structure art fields (Bourdieu 1983), so meaning structures concerning politics may be said to result from field forces. We do not think it is plausible, however, that field forces dictate the meaning structure associated with a particular position in the field. More probably, the reverse effect applies in our case: Meaning structures emerge within collectives due to the members who interact and field position results from the emerged meaning structure. In the next section, we substantiate this conjecture with an analysis of the meaning structures of different groups within the $\mathrm{CH}$ collective.

\subsection{Comparison of groups within a collective}

Statistics presented in Table 1 inform us that the $\mathrm{CH}$ collective is comprised of two types of members: Artists and Philosophers. Artists have received professional training in the arts and art is their main occupation. In $\mathrm{CH}$, they promote an activist, politically and socially engaged perspective on art. Philosophers are affiliated with academic institutions, writing books and papers in political and social philosophy. Their perspective on art is grounded in political philosophy and history in correspondence with the principles of critical post- and neo-Marxist theory, feminist theory, the Eastern tradition of postcolonial critics, and reflections upon the history of Western civilization, symbolic power of the state, citizens' rights and freedom.

These two groups are also formally separated (Girvan and Newman 2002) in the network of their interactions (Fig. 4). The four Artists interact very frequently with each other but they interact less with the academics, who also interact relatively frequently with each other, even though their level of interaction is lower than that among the artists. The Artists and Philosophers, then, are social groups in terms of their interaction patterns.

The interviews show that the groups are recognized by $\mathrm{CH}$ members themselves. Artists criticize Philosophers and vice versa. Their criticisms concern the application of norms and values that are common to the other member's main field but foreign to their own field. The Philosophers criticize the Artists' use of theory and are skeptical about their emotional rather than rational behaviour, thus reproducing dispositions and values associated with the academic field:

There were contradictions because there are artists and non-artists $<\ldots>$ Those artists are not thinkers. They are not used to thinking rationally (CC Philosopher, interview). 


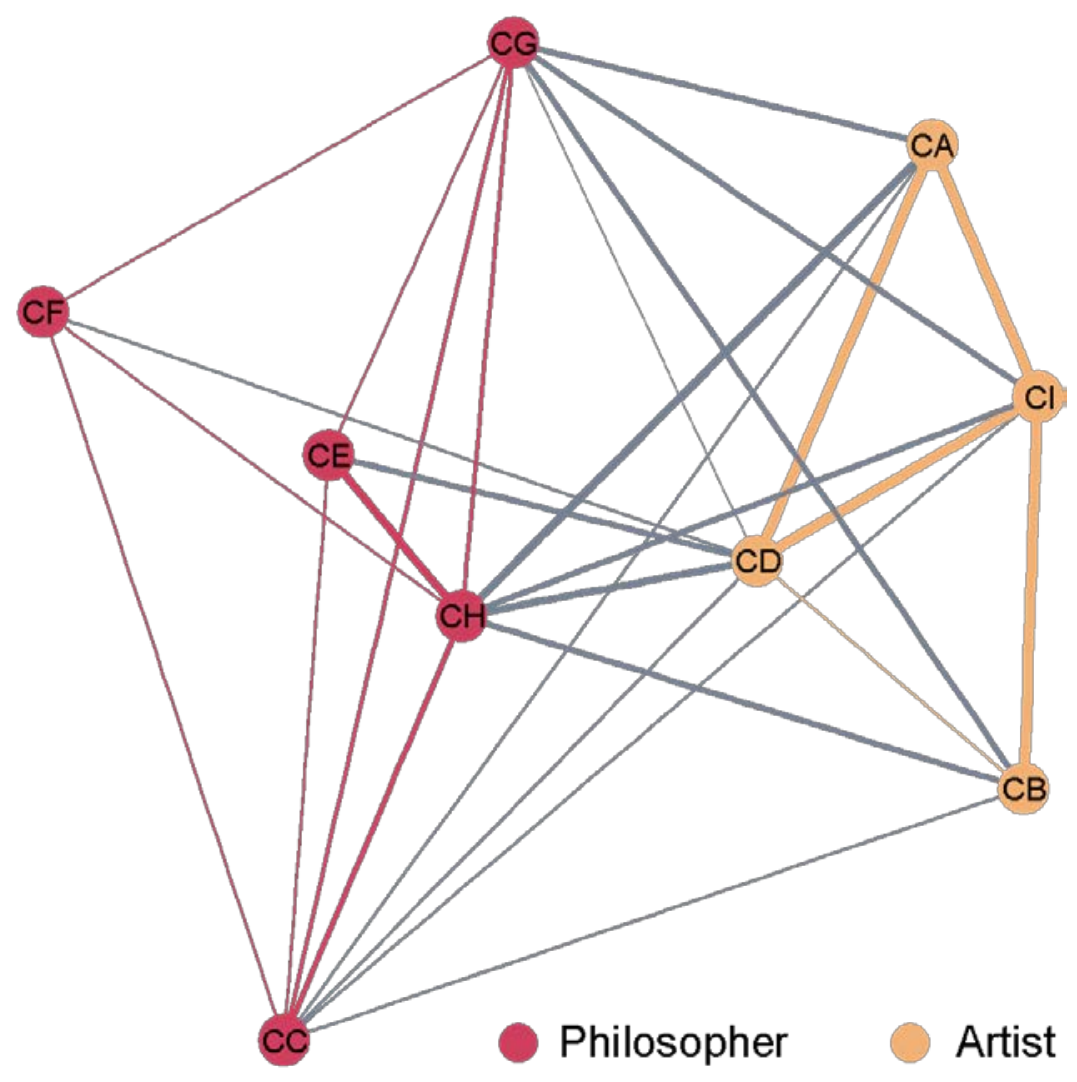

Fig. 4 The structure of interpersonal relations (interaction) among $\mathrm{CH}$ members

Nodes and ties coloring are according to the results of the Newman algorithm for subgroups detection (modularity = 0.06). Line widths stand for quantified interaction frequency scaled from 'interacting once a month or less frequently' to 'interacting every other day or more often'.

The Artists stress the Philosophers' secondary role in artistic practice within the collective:

Before we are on stage, everything is criticized, blamed, questioned, kicked. When we are on stage, I am the director, and there's my full totalitarian power $<\ldots .>$ Because I have the vision I normally take it [power]. (Cl Artist, interview)

$<\ldots>$ all the life of artists revolves around this production process, and it is more natural for us that we devote more time to collective projects than they [Philosophers] do. (CD, Artist, interview)

Are group structure and variation in members' primary field of occupation relevant to the meaning structure within the $\mathrm{CH}$ collective? Do meaning structures emerge from the confrontation of members of two different fields of symbolic production? Let us have a look at the structure of concept links that are shared by at least three Philosophers or by at least two Artists in CH (Fig. 5). We set a slightly higher threshold for Philosophers because they added many more words to our corpus. 


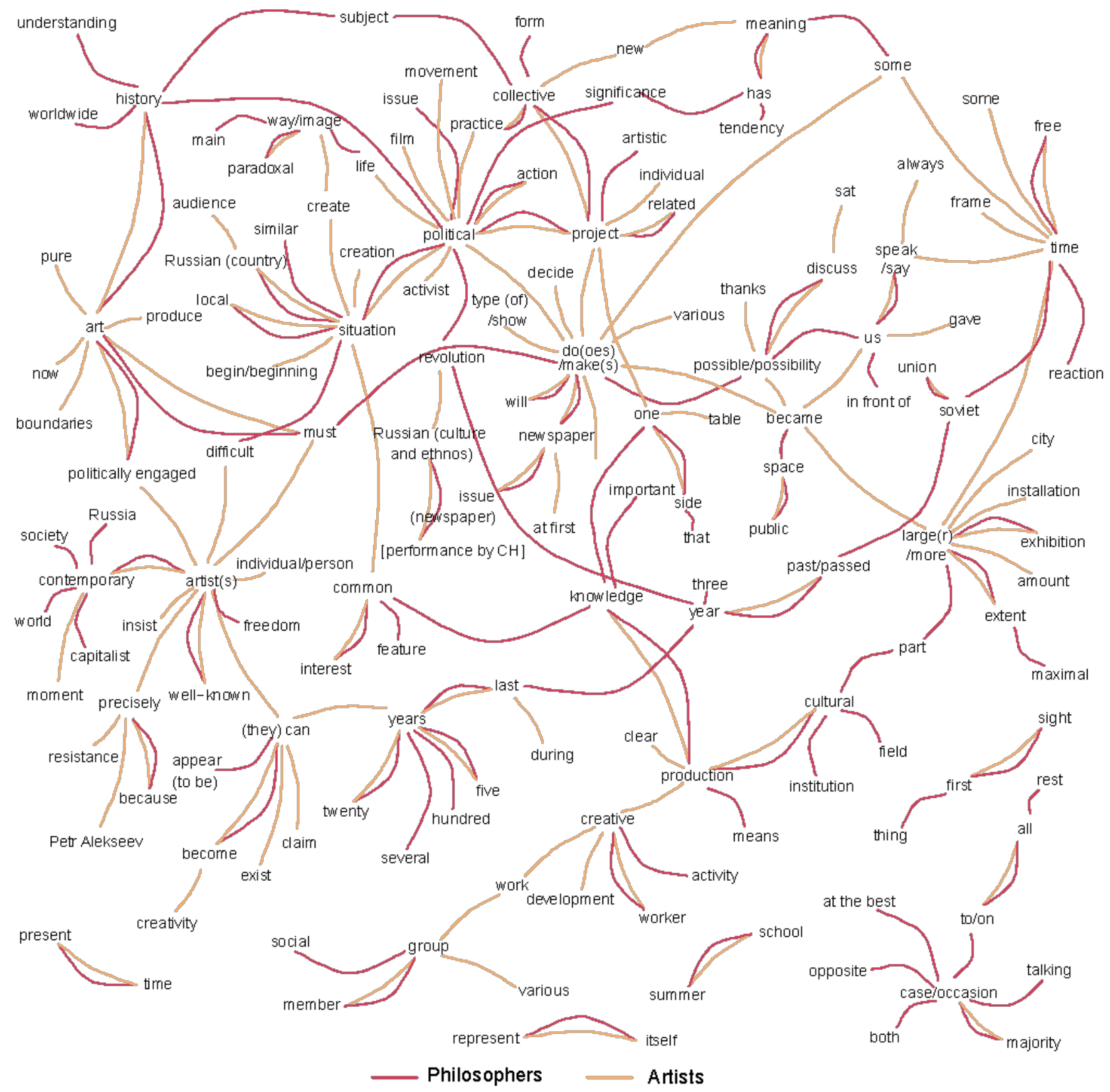

Fig. 5 Semantic network of shared concept links within or across groups in $\mathrm{CH}$

We computed the percentage of concept links shared across groups in $\mathrm{CH}(30,5 \%)$ and the percentage of the links unique to Philosophers $(33,2 \%)$ and to Artists $(36,3 \%)$. First of all we should note that a significant part of concept links are shared both by Artists and Philosophers. Even though Artists and Philosophers have different backgrounds and primary contexts, they have achieved some quite common ground in their meaning structures.

Politics, a central issue for $\mathrm{CH}$ meaning structures according to our previous analysis, is the most central concept in the semantic network of the collective overall (Table 4), used most frequently in concept links (55 times) and linked to more concepts than any other (13). 
Table 4. Concepts, most frequently used in concept links shared in $\mathrm{CH}$.

\begin{tabular}{ll}
\hline Concept & $\begin{array}{l}\text { Co-occurrences with } \\
\text { other concepts } \\
\text { (degree centrality) }\end{array}$ \\
\hline political & 55 \\
side & 53 \\
one & 52 \\
large(r)/more & 37 \\
art & 36 \\
year & 34 \\
case/occasion & 33 \\
production & 33 \\
history & 32 \\
situation & 32 \\
\hline
\end{tabular}

Links to political that are shared by both the Artists and Philosophers occur quite frequently and include political-action (used 8 times), political-situation ( 7 times), and political-project (4 times).

Politics is important to the meaning structures of both $\mathrm{CH}$ groups. This is a topic on which their meaning structures converge. Nevertheless, as the statistics indicate, most of the concept links are idiosyncratic to one of the two subgroups: $36,3 \%$ are only used by the Artists and $33,2 \%$ - only by the Philosophers. Notwithstanding the common use of links related to politics, the semantic network suggests that the Artists elaborate much more on art as a creative process (see orange links in Fig. 2), idiosyncratically sharing such links as creative-work, creative-development, creative-production, art-now, boundaries-art, art-produce, and pure-art.

In addition, as the Artists' most central concepts show (Table 5), they elaborate on such concept as artist as much as they do on political and also on art and creative. It mirrors practice and dominant meaning structures in the artistic field: art as a pure and creative process driven by the artist as a solitary creator. These concepts are not among the Philosophers' most central ones.

Yet still, for the Artists political is one of the most central concepts (Table 5), which is most often encountered even among their most frequent idiosyncratic links (Table 5). However, as their idiosyncratic links to political indicate, when they express the joint focus of the collective on political engagement, they still address it as a creative process and practical activities, most frequently linking political to such concepts as movement, film, life. 
Table 5. Most frequently used idiosyncratic concept links of Artists and Philosophers and most central concepts in their idiosyncratic semantic networks

\begin{tabular}{|c|c|c|c|}
\hline \multicolumn{2}{|l|}{ Artists } & \multicolumn{2}{|l|}{ Philosophers } \\
\hline Concept & $\begin{array}{l}\text { Co-occurrences } \\
\text { with other concepts } \\
\text { (degree centrality) }\end{array}$ & $\begin{array}{l}\text { Co- } \\
\text { oth } \\
\text { ldes }\end{array}$ & $\begin{array}{l}\text { o-occurrences with } \\
\text { ther concepts } \\
\text { legree centrality) }\end{array}$ \\
\hline political & 9 & political & 7 \\
\hline $\operatorname{artist}(\mathrm{s})$ & 9 & case/occasion & 6 \\
\hline large(r)/more & 7 & situation & 5 \\
\hline situation & 7 & years & 5 \\
\hline art & 7 & year & 5 \\
\hline do(oes)/make(s) & 6 & contemporary & 5 \\
\hline project & 6 & history & 5 \\
\hline can & 5 & project & 4 \\
\hline precisely & 4 & collective & 4 \\
\hline creative & 4 & cultural & 4 \\
\hline Concept link & Frequency of usage & Concept link & Frequency of usage \\
\hline life-political & 6 & large(r)/more-part & 12 \\
\hline always-speak/say & 4 & last-year & 11 \\
\hline political-movement & 4 & both-case/occasion & 9 \\
\hline do(oes)/make(s)-some & 4 & first-thing & 8 \\
\hline $\begin{array}{l}\text { do(oes)/make(s)-type } \\
\text { (of)/show }\end{array}$ & 4 & subject-history & 7 \\
\hline film-political & 4 & some-meaning & 7 \\
\hline during-last & 4 & at the best-case/occasion & 7 \\
\hline precisely-artist(s) & 3 & maximal-extent & 7 \\
\hline now-art & 3 & way-life & 6 \\
\hline boundaries-art & 3 & means-production & 6 \\
\hline
\end{tabular}

The view of political engagement as a creative process is also reflected in the quotes in which the Artists' most frequent idiosyncratic concept links are contextualized:

This does not mean that political film denies the viewer aesthetic experience and emotional involvement. This is often a weakness of many contemporary works. The tradition of political film throughout its development has elaborated a whole set of peculiarities of its ideologically-aesthetical impact (the effect of alienation, elements of surrealism, dialogical construct... to name but a few). I think political film is a multilevel composition combining emotional impact and comprehensive intellectual analysis. Paradoxically, we must learn to touch the hearts of the viewers without amusing them. (CA, Artist, written text) 
In contrast, the Philosophers elaborate on concept links central to leftist political philosophy. Among their most frequent idiosyncratic links are subject-history, way-life, means-production (Table 5).

They also focus on more abstract and large-scale notions, reflecting on society, culture and economics in the historical perspective. For instance, their most central concepts are related to history, time (contemporary, year) and culture (Table 5).

Unlike the Artists' idiosyncratic concept links to political, referring to creative process and practical activities, the Philosophers' links to this concept refer to historical context (political-history, politicalrevolution), theorizing political processes in a broader perspective (Table 6):

From idleness, from nothing to do, human work is born. This is true not only in the economic sphere (where Marx has shown the connection between leisure and labor), but also in political history, where the paradox of leisure results in post-revolutionary excess, like post-Jacobinist terror or the Russian stagnation of the 90-s. This is also true in aesthetical, poetic activity, which is by definition during leisure and for amusement, puts things on hold and shows the work of leisure. (CC, Philosopher, written text)

Table 6. Idiosyncratic links of Philosophers to concept political

\begin{tabular}{lc}
\hline Linked concepts & $\begin{array}{l}\text { Frequency of } \\
\text { usage }\end{array}$ \\
\hline history & 5 \\
significance & 5 \\
revolution & 3 \\
issue & 3 \\
\hline
\end{tabular}

Although their meaning structures clearly derive from different fields, the concept links that the Artists and Philosophers share seem to reflect a common understanding that results from intense collaboration and interaction. Consider the most frequently used shared concept links to the most central concept political. An Artist expresses one of these links political-situation in a way that is very similar to a Philosopher elaborating on the other link political-action, both criticizing the supposed autonomy of art:

I think, it all started when the political situation in the country and the world began to change. When the ongoing events could not be ignored any longer. And then European projects started to grow stronger. This is also related to crisis; the whole world was in crisis. Altogether, more and more people came to understand that art can't move further while being positioned in an absolute sovereignty, in which it had been before. What is the issue now? The main debate is along the following line: May an artist insist on his sovereignty, or should ways be searched for in alternative projects? And if you work alone, you are someone else, rather an agent (CB, Artist, interview).

Realizing one of its liberal freedoms - self-expression - in the space of the aesthetical, the artistic community lives with an illusion of an internal protest and revolution, 
objectively continuing to serve the capital and enrich it with new images. <...> The freedom of artist as a subject of actual history may be expressed not in a life of euphoric community in itself, but in action freeing the limits of the aesthetical, breaking the boundaries of community autonomy, directed to society in general, through political action. <...> Establishment of artistic autonomy too often looks only like a peaceful demonstration, controlled and restrained with a living wall of water jets and police batons. Even if art in its autonomy claims the right to make a distinction in society as a whole, it holds and fixes upon a position strictly allocated by power surrounding it. But what about violence which the peaceful demonstration is fraught with? In other words, can we expect that art breaks the conventions of contemporary society, regaining its lost significance, relevance? Following Foucault, we can show that autonomy is a natural result and the aim of regulatory disciplinary practices. (CE, Philosopher, written text)

Members of the collective acknowledge that interaction with representatives of the other field has changed their opinions. In the quote below, a Philosopher uses one of the shared concept links politically engaged-art in a reflection on how the meaning structure around art, politics, and knowledge emerged during a period of joint collective practices and interactions within $\mathrm{CH}$ :

On the one hand, we are between Piter and Moscow, on the other - between art and philosophy, theory. <...> first time the discussions were incredible, they were very hot. There were many themes related to discussion of what politically engaged art is, what real art is, what contemporary art is and how politics and art are related, as well as art and knowledge, and left and right, and so on. Everything was revolving around this triangle. Different people were the opponents, this circle kept changing, because one is taking this side, the other one - that side. These discussions are good because in the process a person often changes opinion. He argues, argues, defends something, and then comes to something else. So, somehow we passed this period and the project was established. (CH Philosopher, interview)

The meaning structures of Artists and Philosophers overlap but at the same time they reflect the field that functions as their primary frame of reference. Concept links shared across groups show traces of both fields and, as inspection of the textual contexts shows, shared meaning structures emerge because representatives of different fields engage in joint practice and interpersonal relations. To us, it is plausible that the confrontation between Artists and Philosophers has given rise to a meaning structure in which political engagement is important. This emergent meaning structure positions the collective within the art field because it entails a position-taking between the autonomy and heteronomy poles. Fields meet because members of different fields interact and this affects the position-taking and hence the field position of the members. 


\section{Conclusion}

Both field and institutional perspectives intertwine material and symbolic structure, mapping the space of behavior, properties, and ties on the space of meanings. We very much value the ambition. We also subscribe to the idea that fields and institutions impose systems of classification on their members that resist change and regulate the meanings that members attribute to behaviors, properties, and ties. However, these perspectives seem to underestimate the role of the members of fields and institutions in putting the relationship between cultural meanings and social structure into practice, especially when individuals join in groups of mutual support and collective practice. Based on the idea of the capability of groups to generate culture (Fine 1979), we conceptualize agency in the dual ordering of the social and the cultural not as the property of an individual person but as the property of a small group. We define a group as a set of persons involved in regular and engaging interactions. While interacting, humans may be confronted with meanings assigned to behaviors, properties, or ties that differ from their own. If interaction is regular, engaging, and important to people, it can be consequential to their meaning structure.

In our analyses, we find evidence both for field-imposed meaning structures and context-specific meaning structures that emerge by means of interaction and joint practice in groups. Concept links that are related to the core struggle within a field of contemporary art, namely the definition of art, are used by members of both collectives. Where members of different fields meet, as in the $\mathrm{CH}$ collective, meaning structures reflect practice in the field in which a person is primarily occupied. If we zoom into the ways in which concept links are used, however, we notice that members of one field adjust their meaning structure to the meaning structure of the other field. These results suggest that we should not focus exclusively on objective relations, as Bourdieu has argued.

We have purposefully selected a rather peculiar setting to demonstrate our ideas about imposed and emergent meaning structures, namely artistic collectives. It has been argued that a group's coherent artistic style, techniques, and topics emerge thanks to discussions between members who form a shared 'vision' (Farrell 2003). The selected collectives strongly encourage collaboration, so there is a lot of interaction and the interaction is quite engaging. Interaction, then, may affect meaning structures in artistic collectives and, perhaps, other collectives emerging to pursue common goals, like start-ups, exploratory research groups, groups of political activists, more strongly than in more formalized settings. In addition, creative practice as studied here is hardly regulated in comparison to bureaucratic practice, such as encountered in a welfare organization (Mohr 1994) or a city administration (Meyer et al. 2012). Within highly regulated practices, imposed meaning structures are likely to be much stronger and it would be much more difficult to pinpoint emergent meaning structures. Our focus on interaction makes us speculate that regulation of a practice enforces imposed meaning structures by restricting interpersonal interaction with members of other fields or institutions. With less interaction among members of different institutions or fields, there is less need and fewer opportunities to play on the gaps and contradictions of different meaning structures.

In contrast to formal approaches used by institutional and field theory scholars based on category coding (Mohr 1994, 1998; Mohr and Lee 2000; Mohr and Neely 2009), we propose a mixed methods approach to the duality of social structure and meaning structure without coding. We apply semantic network analysis to free narratives as the textual data to map meanings as recommended by (Lee and Martin 2015), but we 
incorporate the author of the texts and focus only on concepts and concept links that are shared by members of the same group, collective, or field. Admittedly, this is a very restricted use of social structure in the analysis of meaning structures. In our experience, it still makes a huge difference. We have initially tried several ways of analyzing the semantic network in isolation but this did not yield insights that matched, let alone extend our ethnographic knowledge about the collectives. The comparisons between groups and collectives, however, make sense.

Finally, we want to reflect on an important question related to usage of formal social network analysis techniques when analyzing meaning structures. Displaying the concept links as a network, as we have done in Fig. 1 and 5, it is tempting to read sequences of links as sentences or stories. In all honesty, we initially yielded to this temptation. But when we took into account the textual context of the links, we soon discovered that it is misleading to interpret indirect links in this type of semantic networks. As a consequence, we doubt that measures accounting for overall network structure, that is, the core of social network analysis, are useful for analyzing semantic networks of direct collocation when focusing on meaning structures. In this kind of analysis, our network visualizations are merely convenient ways of jointly presenting dyads of concepts that signal meaning structures. As a consequence, we limited ourselves to usage of dyad-based network statistics, such as degree centrality in this paper. Elsewhere, we experiment with statistical models that focus on local micro-patterns of social ties and concept links (references to authors' own work).

\section{Funding}

This work has benefited from the support of Russian scientific foundation for humanities (15-03-00722 "Coevolution of knowledge and communication networks: structural dynamics of creative collectives in European cultural capitals", 2015-2017) and the Centre for German and European Studies - Bielefeld University and St. Petersburg State University supported by the DAAD with funds from the German Foreign Office.

\section{Acknowledgements}

The authors express their gratitude to those who helped in data collection and processing: Maria Veits, Olga Volkova, Alexey Evstifeev, Alexander Kopiy, and Olga Nikiforova. We are very grateful for comments received on this paper from Loet Leydesdorff, Dafne Muntanyola, Margarita Kuleva, and Anisya Khokhlova as well as the participants of the 36th Sunbelt Social Networks Conference of the International Network for Social Network Analysis in 2016, workshop Network Theory and Methods: Combining Structure, Content and Meanings? in 2015, European Sociological Association conference in 2015, 34th Sunbelt Social Networks Conference of the International Network for Social Network Analysis in 2014, International conference Networks in the Global World in 2016 and 2014, and European Social Networks Conference in 2014. 


\section{References}

Becker, H. S. (1982). Art worlds: Univ of California Press.

Bian, Y., Breiger, R., Galaskiewicz, J., \& Davis, D. (2005). Occupation, class, and social networks in urban China. Social Forces, 83(4), 1443-1468.

Bourdieu, P. (1983). The field of cultural production, or: The economic world reversed. Poetics, 12(4-5), 311-356.

Bourdieu, P. (1990). The logic of practice: Stanford University Press.

Bourdieu, P. (1996). Physical space, social space and habitus. Rapport, 10, 1996.

Bourdieu, P. (1998). Practical reason: On the theory of action: Stanford University Press.

Bourdieu, P., \& Johnson, R. (1993). The field of cultural production: Essays on art and literature: Columbia University Press.

Bourdieu, P., \& Wacquant, L. J. (1992). An invitation to reflexive sociology: University of Chicago press.

Breiger, R. L. (2000). A tool kit for practice theory. Poetics, 27(2), 91-115.

Breiger, R. L. (2005). Culture and classification in markets: An introduction. Poetics, 33(3-4), 157-162.

Breiger, R. L., \& Puetz, K. (2015). Culture and networks. International encyclopedia of social and behavioral sciences (2nd. ed ed.). New York: Elsevier.

Carley, K. (1986). Knowledge acquisition as a social phenomenon. Instructional Science, 14(3-4), 381-438.

Carley, K. (1994). Extracting culture through textual analysis. Poetics, 22(4), 291-312.

Dahlander, L., \& McFarland, D. A. (2013). Ties that last: Tie formation and persistence in research collaborations over time. Administrative Science Quarterly, 58(1), 69-110.

Danowski, J. A. (1982). Computer-mediated communication: A network-based content analysis using a CBBS conference. In M. Burgoon (Ed.), Communication yearbook (Vol. 6, pp. 905-924, Vol. 1). Beverly Hills, CA: Sage.

De Nooy, W. (2003). Fields and networks: correspondence analysis and social network analysis in the framework of field theory. Poetics, 31(5), 305-327.

De Saussure, F., \& Hidayat, R. S. (1988). Pengantar Linguistik Umum: Gadjah Mada University Press.

Diesner, J. (2013). From texts to networks: detecting and managing the impact of methodological choices for extracting network data from text data. KI-Künstliche Intelligenz, 27(1), 75-78.

DiMaggio, P. (1986). Structural analysis of organizational fields: A blockmodel approach. Research in organizational behavior.

DiMaggio, P. (2011). Cultural networks. In J. Scott, \& P. J. Carrington (Eds.), The SAGE handbook of social network analysis (pp. 286-310): SAGE publications.

Erickson, B. H. (1988). The relational basis of attitudes. In B. Wellman, \& J. Bercovitz (Eds.), Social structures: A network approach (Vol. 99, pp. 99-121). Cambridge, NY: Cambridge University Press.

Erickson, B. H. (1996). Culture, class, and connections. American journal of sociology, 217-251.

Farrell, M. P. (2003). Collaborative circles: Friendship dynamics and creative work: University of Chicago Press.

Fine, G. A. (1979). Small groups and culture creation: The idioculture of little league baseball teams. American sociological review, 733-745.

Friedland, R., \& Alford, R. R. (1991). Bringing society back in: Symbols, practices and institutional contradictions.

Girvan, M., \& Newman, M. E. (2002). Community structure in social and biological networks. Proceedings of the national academy of sciences, 99(12), 7821-7826.

Godart, F. C., \& White, H. C. (2010). Switchings under uncertainty: The coming and becoming of meanings. Poetics, 38(6), 567-586.

Gondal, N., \& McLean, P. D. (2013). Linking tie-meaning with network structure: Variable connotations of personal lending in a multiple-network ecology. Poetics, 41(2), 122-150.

Lee, M., \& Martin, J. L. (2015). Coding, counting and cultural cartography. American Journal of Cultural Sociology, 3(1), 1-33. 
Meyer, R., Jancsary, D., Höllerer, M. A., \& Barberio, V. Call a Man a Customer..: Social Categories and Power in Public Sector Discourse. In The Academy of Management Annual Meeting 2012, 2012

Mische, A., \& White, H. (1998). Between conversation and situation: Public switching dynamics across network domains. Social Research, 695-724.

Mohr, J. W. (1994). Soldiers, mothers, tramps and others: Discourse roles in the 1907 New York City Charity Directory. Poetics, 22(4), 327-357.

Mohr, J. W. (1998). Measuring meaning structures. Annual review of sociology, 345-370.

Mohr, J. W. (2000). Introduction: Structures, institutions, and cultural analysis. Poetics, 27(2-3), 57-68.

Mohr, J. W., \& Lee, H. K. (2000). From affirmative action to outreach: Discourse shifts at the University of California. Poetics, 28(1), 47-71.

Mohr, J. W., \& Neely, B. (2009). Modeling Foucault: Dualities of power in institutional fields. In Institutions and Ideology (pp. 203-255): Emerald Group Publishing Limited.

Mohr, J. W., \& Rawlings, C. (2010). Formal models of culture. Hall, J., Grindstaff, L., and cheng Lo, M., editors, Handbook of Cultural Sociology, 118-128.

Mützel, S. (2009). Networks as culturally constituted processes a comparison of relational sociology and actor-network theory. Current Sociology, 57(6), 871-887.

Nerghes, A., Lee, J.-S., Groenewegen, P., \& Hellsten, I. (2015). Mapping discursive dynamics of the financial crisis: a structural perspective of concept roles in semantic networks. Computational Social Networks, 2(1), 16.

Pachucki, M. A., \& Breiger, R. L. (2010). Cultural holes: Beyond relationality in social networks and culture. Annual review of sociology, 36, 205-224.

Porter, M. F. (1980). An algorithm for suffix stripping. Program, 14(3), 130-137.

Roth, C., \& Cointet, J.-P. (2010). Social and semantic coevolution in knowledge networks. Social Networks, 32(1), 16-29, doi:10.1016/j.socnet.2009.04.005.

Schultz, J., \& Breiger, R. L. (2010). The strength of weak culture. Poetics, 38(6), 610-624.

Sinclair, J. (1991). Corpus, concordance, collocation: Oxford University Press.

Thornton, P. H., Ocasio, W., \& Lounsbury, M. (2012). The institutional logics perspective: A new approach to culture, structure, and process: Oxford University Press on Demand.

Umphress, E. E., Labianca, G., Brass, D. J., Kass, E., \& Scholten, L. (2003). The Role of Instrumental and Expressive Social Ties in Employees' Perceptions of Organizational Justice. Organization Science, 14(6), 738-753.

Vaisey, S., \& Lizardo, O. (2010). Can cultural worldviews influence network composition? Social Forces, 88(4), 1595-1618.

White, H. C. (1992). Identity and control: A structural theory of social action: Princeton University Press.

Wittgenstein, L. (1953). Philosophical Investigations (Vol. 50, Section). New York.

Yeung, K.-T. (2005). What does love mean? Exploring network culture in two network settings. Social Forces, 84(1), 391-420. 